\title{
A Qualitative Oriented Study About IT Procurement Processes: Comparison of 4 European Countries
}

\author{
Michael Schiessl and Sabrina Duda \\ eye square GmbH, Schlesische Str. 29-30, D-10997 Berlin, Germany \\ schiessl@eye-square.com, duda@eye-square.com
}

\begin{abstract}
This study shows that in a qualitative study a small sample size is sufficient to gain interesting results and show differences between the procurement of IT services in different countries. It demonstrates how a requirements analysis can be conducted in a very early phase of a web development project. For the website of an IT company which sells products worldwide the needs of potential users of its website should be identifed. With 8 users each from Germany, Switzerland, Belgium and Spain, an in-depth interview was conducted; after that some page drafts were shown. The users were from different hierarchy levels and from companies of varying sizes; all involved in the IT procurement process. The study showed who is involved in the different stages and what is relevant in each stage. The distribution of responsibilities was different in each country. The study gave insights into how to support potential buyers during the IT procurement process and how to adapt the web pages to local needs.
\end{abstract}

Keywords: International Usability, Requirement Analysis, IT Procurement, Web Usability, User Test.

\section{Introduction}

An international IT company with headquarters in an English speaking country has conducted a usability study in different European countries during the redesign of their website. The study was conducted at a very early stage of development. The website shall support employees of companies who plan to buy IT systems. A theoretical model about the processes of IT procurement was already in existence. However it was unclear to which extent employees are involved in each of the six stages; furthermore, it was unclear how tasks were split. This study should shed light on how the real IT procurement processes are carried out, with a sample of employees from different hierarchy levels (from Technician to CTO). This study focused on the results of in depth-interviews. Additionally some already existing drafts of the web pages were evaluated; here it was especially important how users found their way from the company page to the country specific page.

\section{Research Questions}

For the website of an IT enterprise which is selling its products worldwide, the needs of potential users of the website were to be identified. 
- How is the process of IT procurement going on? Who is involved in which stages of IT procurement?

- What is important when choosing a supplier?

- How do users like the example web pages?

\section{Method}

With eight users each in Germany, Switzerland, Belgium and Spain an in-depth interview (lasting 2 hours) was conducted. These users were involved in the IT procurement processes in their company. The users were from different hierarchy levels, and the company size was varying. In total we had 32 subjects (31 male, 1 female): 2 x CEO/CTO, 9 x Senior IT Manager, 8 x Operational IT Manager, 8 x Technical Specialist, 5 x Project Manager. Mean age was 36 years (25-61). All had received a higher education.

These are the stages of IT procurement we explored in detail:

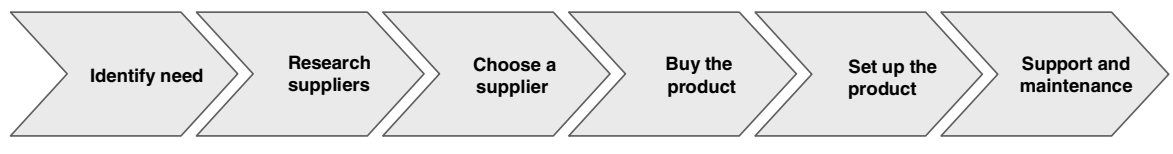

Fig. 1. Stages of IT Procurement Process

\section{Results}

\subsection{Stages of IT Procurement - Who Is Involved?}

Results surprisingly showed that only the very highest level and the lowest level of the hierarchy are involved in only a few stages: The few top-level subjects (CEOs) of the sample are undoubtedly more involved in the earlier stages; low-level positions (e.g. technicians) are involved in fewer stages (research, set-up and maintenance).

The higher levels of the hierarchy are involved in almost every stage of IT procurement; especially in Germany and Switzerland, where the higher management seems to have a need to control all stages.

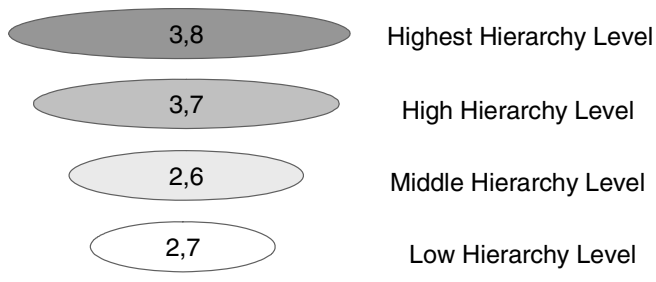

Fig. 2. Mean number of stages in which employees are involved: All countries

In Germany and Switzerland the subjects tended to be involved in more stages. The higher up the ladder they are, the higher their involvement is! The people with higher 
responsibility in Germany and partly in Switzerland care about everything. They may not delegate as much as those in the same position in Spain and Belgium. In Belgium and Spain people seem to be concentrated more on their specific tasks. Highest management in Germany wants information about every stage of the process. The Germans have a high demand for technical details. They are more concerned about controlling everything.
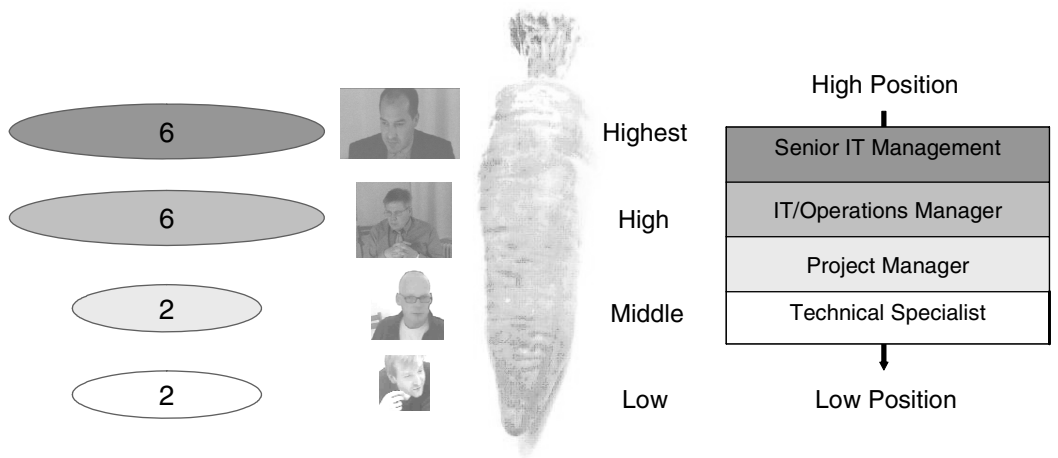

Fig. 3. Mean number of stages in which employees are involved: "Carrot Model" Germany

In Spain and Belgium, the management wants only the information they really need. The image is the most important information for the CEOs. They are less interested in details. In Spain the people responsible have stricter divisions concerning their tasks! High management only has a few tasks; usually to identify needs.

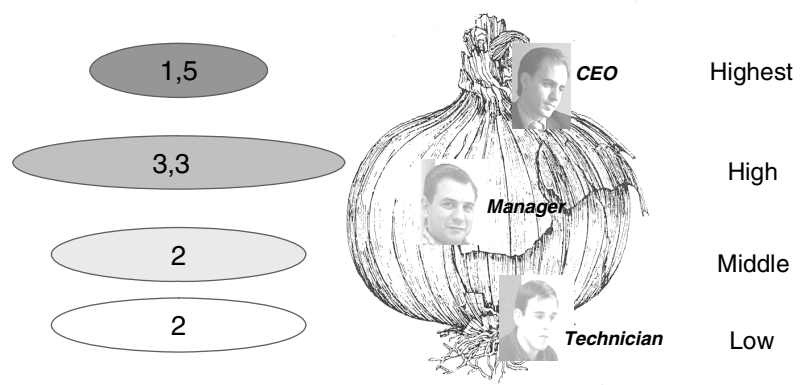

Fig. 4. Mean number of stages in which employees are involved: "Onion Model" Spain

The identification of the need is mostly initiated by interior triggers. External facilitators like marketing material and websites play a very minor role.

In the first stage of procurement: identifying needs, people from all levels in the hierarchy are involved (the management is always involved). The lower levels (technicians) tend to be involved in the last stages such as, set up and maintenance. 


\begin{tabular}{|c|c|c|c|c|}
\hline & Highest Level & High Level & Middle Level & Low Level \\
\hline Germany & 6 & 6 & 2 & 2 \\
\hline Spain & 1,5 & 3,3 & 2 & 2 \\
\hline Belgium & 3 & 2,5 & 2,5 & 3 \\
\hline Switzerland & 4,5 & 3 & 4 & 4 \\
\hline
\end{tabular}

Fig. 5. Mean number of stages in which employees are involved: All countries

\subsection{Identify Needs}

Needs are typically identified through a customer demand, technical reasons or for the purpose of cost cutting. The impulse for the idea for a new system is not generated externally (e.g. marketing, vendors), but internally (e.g. professional department, coworkers, clients, ideas of the management).

Usually everybody is involved because it is an important issue (the management is always involved). This reveals that the marketing should be directed at all levels in a hierarchy (conveyance both of image and technique).

\subsection{Research Suppliers}

The search for a supplier is usually initiated either through contacting a known supplier - via phone preferably! - or one that has been recommended (many have established relationships, fixed suppliers).

Quickly this list is reduced by taking in technical and pricing considerations. At this point, the web is sometimes used to check references or company sizes, but less often to check products. The subjects do not usually look for products on the supplier's website, but rather check other websites (for field reports, case studies, the financial standing of the supplier) because they are neutral.

During the phase of searching for a product, presentations of the product or visits to other clients with the product already up and running are important. On average a rather small amount of 3-6 suppliers were actually contacted. The others were quickly eliminated based on reasons like inappropriate techniques or too high prices. The first contact with a supplier must be recognized to be competent, offering personal presentations of products or on site inspection.

\section{Quotes}

- "Normally we work with 3 suppliers because we have the tendency to trust more the 'familiar' suppliers.. who already know us, [...]. It is important to work with several suppliers to generate competitiveness between each one of them." (Spanish user)

- " $[. .$.$] first of all you have to look at the company references. Then you have to find$ out if it is a small business (eg.20 employees) or a big business (eg. 2000 employees). In today's economic situation there are too many companies being 
bought out and as a result products are no longer supported. The point is, I need a company with a certain market presence and reference. Surely we place orders between 5-10 thousand Euros; when it is more we really look for these things." (Geramn user)

\subsection{Choose a Supplier}

When deciding on a supplier, technical matching, flexibility, adaptation of the product to the individual needs, service and service contracts very deemed priorities and only at the very end the is the price considered important. Top decision makers expect to be contacted and get special individual service. They do not want to look through marketing material or search the web.

The information that is important when choosing a product is similar to that of when searching for a product. The technical matching of the product (does it meet the desired requirements), whether the price can be individually customized (adaptation), and the validity of the servicing and warranty must be explored. Service and flexibility are absolutely crucial when actually choosing a supplier. When the client has chosen a supplier sometimes a phase of negotiation starts (extras, individual adaptations, service contracts).

Important factors when choosing a supplier are whether a good service is offered in combination with flexibility (of products). This dictates that it should be possible to buy separate modules (not only total packages). The system should be able to be integrated into existing parts (compatibility) and should be able to adapt to a client's individual needs.

To govern this efficiently should assign one steady key-account manager from the beginning onwards. Investment in technically well-trained account managers embodied with the authority to make an individual pricing policy appears to be promising. For higher management a phone call or personal presentation would be convincing.

Because higher management have little time and do not bother to search actively they like to have things presented to them. They like to get specific, tailored and condensed information via phone (quicker than the web or studying marketing material). Technical specialists and lower-level positioned people will be convinced more by technical facts, case studies, test reports.

All in all, former state-run telecom companies and big international companies (e.g. IBM, Microsoft) are considered as being relevant suppliers. Other companies have to be present locally and offer service on site. It is important for international suppliers to provide service on site. They should have a local branch and local contact partners. People worry about availability of quick service on site and spare parts in their country.

In the study it was discovered that what seemed to hinder most people in seeing the IT company of this study as a relevant supplier is the fact that they seem to have had relatively little exposure to it. In Spain and Belgium everyone knew them and in Switzerland $2 / 3$ of the subjects, but in Germany only half of the subjects knew the company. 


\section{Quote}

- "Well, I think the bottom line is that they are not very well spread out in Germany. They are not present in Germany or Berlin. They don't offer the same service that they do in their home country." (German user)

\subsection{Buy the Product}

The management and the financial department confirm their decision - then the product is bought. Most common is phoning (oral confirmation of order) and faxing the signed offer. Sometimes a personal meeting is arranged for signing a contract.

Usually there is no particular procedure taking place immediately after the purchase is confirmed. The client waits for the product and expects the supplier to deliver on time. Occasionally further price negotiations take place. The transparency of the delivery status is important, and the client must be informed early if the timeline cannot be kept.

During the buying phase if everything is going well, there is practically no communication between the supplier and client.

\subsection{Set Up the Product}

During set-up in almost all cases the supplier is on site and installs the product. The reason behind this is that they have to guarantee the product and therefore prefer to do it by themselves. During this phase the contact is mostly face-to-face (sometimes via phone if supplier is not on site). It is important that there is one technician who remains the responsible contact person allowing familiarity and consistency for the client.

\subsection{Support and Maintenance}

When referring to maintenance the personal key-account manager is most important and should ensure that the service should be quick, reliable and around the clock (24 $\mathrm{h} /$ day and 365 days/year). The service contracts are very important and are vital for companies to consider using a supplier again. Support is so crucial that a lack of it can be the starting point for considering another supplier.

Online tools are rarely used and the use of an online tool is not seen. An online tool is too much of an effort especially for people higher in the hierarchy.

\section{Quotes}

- "I want to know how fast they can react in an emergency and replace parts and what parts of Germany they cover. Even if they are a small supplier could they at least do the job within 6 or 7 hours? Or do they have to bring the replacement parts from abroad or is there a warehouse here?" (German user)

- "...maybe it has something to do with the fact that at Camcom there is a contact person who I can call when something doesn't work. When you are dealing with 
5000 Euros, 100 Euros more or less really doesn't matter. What is more important is that there is someone there to phone than to be really lost or desperate." (German user)

\subsection{Evaluation of the WebPages}

Reactions to the example web pages were mixed: In Germany users were more negative about the homepage; in Spain users were more positive; in Belgium and Switzerland comments were more balanced. Few users understood how to get to the specific country site; many complained that the path to the products is too long.

The website should contain country specific content and language (as well as country specific URL; e.g. ".de"). Country specific language is more user-orientated and language is an indicator for country specific content. Websites are not generally used by top managers, people in high positions seem to not do very much research on their own on websites; they might delegate that to people lower in the hierarchy who are not as fluent in English. There must be country (not language!) selection on homepage. Only those products and services should be on the homepage which are available worldwide or hint that this is only an overview and user has to go to his country site to check availability.

\section{Quotes}

- "We like to operate with suppliers that are nearer to us and know about us and our problems, language is important in facilitating confidence." (Spanish user)

- "Like I said, since the end user knows his own language the best, the selection should be at the beginning and should be in German. Maybe there should be a portal introduced and from there it should branch out into the different languages." (German user)

- "'Choose your country/language' must be presented on an earlier page (home) in order to avoid confusion. As a Swiss I am interested in Swiss products, therefore the choices have to be narrowed down right from the beginning..." (Swiss user)

- "I would prefer the "Select your country" in the combo box[...] Right now I think I will get the same page translated into Spanish, but not necessarily a specific page for Spain.” (Spanish user)

- "What confused me was, are the products and services on xy.com also available in Switzerland or not?" (Swiss user)

The link "Global Products and Solutions" which leads to the country-specific pages is unclear to the users. Almost every subject misinterpreted the meaning of this link (they were misled by the word "global"). The supplier determined everything outside its home base as global; therefore the link on the corporate page is named "Global Products and Solutions". But for the people in Germany, Spain, Belgium, Switzerland their country is not global, but local. Almost every subject misinterpreted the meaning of this link (they were misled by the word "global"). 


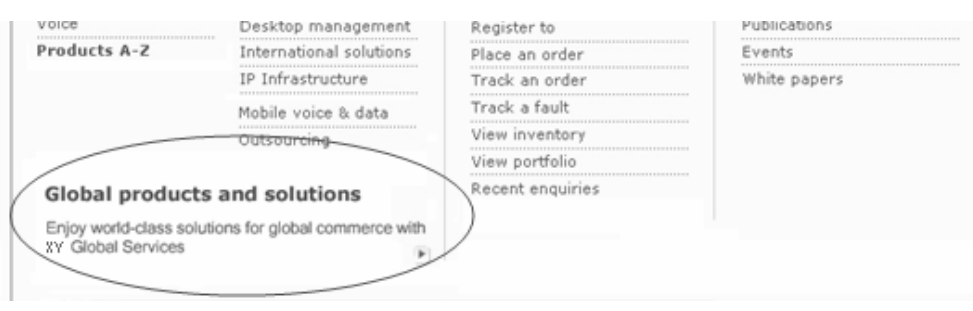

Fig. 6. Misinterpreted link on example web page

\section{Quotes}

- "To me, Global Products and Solutions means solutions for the whole company, for all departments." (Spanish user)

- "I honestly can't imagine what it means. "Global Services"...uh, world-wide data connection, etc..." (German user)

- "Probably solutions for companies with subsidiaries spread across the world." (Belgian user)

- "I think that xy offers a global solution for the whole company in a specific application." (Spanish user)

\subsection{Branding}

From these results it should be gathered that campaigns should focus on image and brand establishment. E.g. show a consultancy situation: satisfied clients talking with the company's account manager. Building on this and as equally important are brand recognition, great service and being local situated. They should be a local presence and it is here marketing and advertisements are important.

\section{Quote}

- "For me, I think its primarily quality. The people who put effort into their advertisements and get across their ideas psychologically, I think would probably also make quality products." (German user)

\section{Summary and Recommendations}

The Internet is not of primary importance during the procurement process. The suppliers site is useful for checking a company's size, references, case studies and information about products in the earlier stages (financial standing is - of course checked on other sites) and later in the process for finding contact information.

During the early stages the subjects regard objective evaluations and test reports of the product on other unbiased websites as more reliable. Typical tasks when visiting a supplier's website (as identified in the study) were to find information about products and to find contact information.

Marketing material was found to be of minor importance; it did not help any of the subjects to initiate buying. However marketing must be intensified to enhance the 
perceived presence of the company in each country and to raise local trust in the company and its products. In this respect marketing should be wary of two phases for the first stages of the IT procurement process it is important to perceive a supplier as being local and on site. During the following stages objective facts about technical features, performance and reliability of the supplier's products gain more importance.

Marketing for the first stages can be concentrated on image. This will have an indirect effect on buying activity. When advertisements are present people will expect that the company branches and account managers are also present. This is considered the first step that will motivate people to add the supplier to their relevant set of suppliers.

The enhancement of the perceived local presence of the company can be achieved through marketing and advertising. The content of such should show account managers in consulting situations and show contact telephone numbers.

For the next stages - the real buying decision - objective, neutral reports are crucial (test reports with benchmarking, case studies, testimonials and experience reports from satisfied clients). In order to be globally successful, one has to be local. For example a local image crossed with a global idea (make the marketing witty: eg. show a British Guard saying "I think Bavarian"). E.g. successful Ikea campaign in Germany plays with being Swedish and at the same time being local: 'Berlin is the Swedish'; Turkish people with blond wigs are shown. 